Revista Temas Socio Jurídicos Vol. $38 \mathrm{~N}^{\circ} 76$ Enero - Junio de 2019

ISSN: 0120-8578

ISSN electrónico: 2590-8901

\title{
EL CONCEPTO DE FAMILIA EN COLOMBIA: UNA REFLEXIÓN BASADA EN LOS APORTES DE LA ANTROPÓLOGA VIRGINIA GUTIÉRREZ SOBRE LA FAMILIA COLOMBIANA EN EL MARCO DE LA DOCTRINA CONSTITUCIONAL
}

Francisco Javier Gutiérrez Negrete*

Recibido: Abril 12 de 2019

Aprobado: Mayo 13 de 2019

\begin{abstract}
RESUMEN:
La familia, tanto como institución social y cultural, es a todas luces un concepto dinámico, cambiante, en constante evolución. Desde las antiguas sociedades griega y romana hasta nuestros días el concepto de familia ha crecido, se ha adaptado y también -casi que simbióticamente- ha propiciado cambios sociales y culturales significativos para la sociedad. En Colombia, tales cambios los anticipó e investigó la antropóloga Virginia Gutiérrez; cambios que se han hecho dramáticamente notorios a partir de la Constitución de 1991. Con el surgimiento de la nueva Carta Política, las personas no heterosexuales, las madres cabeza de familia, los individuos con segundas uniones y las personas que simplemente no han contraído matrimonio bajo el rito católico, han encontrado herramientas jurídicas para reclamar la garantía de derechos subjetivos y objetivos que históricamente se les desconocieron, ya fuese por razones políticas y culturales, o por pretextos sociales y especialmente morales.
\end{abstract}

Citar este trabajo como: Gutiérrez Negrete, F. (2019). El concepto de familia en Colombia: una reflexión basada en los aportes de la antropóloga Virginia Gutiérrez sobre la familia colombiana en el marco de la doctrina constitucional. Temas Socio-Jurídicos, 38(76), pp. 130-154. https://doi.org/10.29375/01208578.3589

* Semillero de Investigación Meleti Nomus Universidad Cooperativa de Colombia (Pasto). Orcid: 0000-0002-8344-6336. Correo electrónico: fjgutierrezn@gmail.com 
A través de una revisión bibliográfica y documental a la luz del método histórico hermenéutico este artículo pretende, en primer lugar, reflexionar sobre la relación entre los hallazgos y aportes de la antropóloga Virginia Gutiérrez y lo desarrollado por la jurisprudencia constitucional a partir de la Carta Política de 1991. En segundo lugar, se busca plantear algunos aportes acerca de los retos y perspectivas sociales y culturales de la familia colombiana en sus diferentes formas y tipologías.

Palabras clave: Familia; adopción; adopción homosexual; matrimonio; unión marital de hecho; matrimonio igualitario; jurisprudencia; antropología; Virginia Gutiérrez.

\title{
THE CONCEPT OF FAMILY IN COLOMBIA: A REFLECTION BASED ON THE CONTRIBUTIONS OF ANTHROPOLOGIST VIRGINIA GUTIÉRREZ ABOUT THE COLOMBIAN FAMILY IN THE FRAMEWORK OF CONSTITUTIONAL DOCTRINE
}

\begin{abstract}
:
The family, a social and cultural institution, is also clearly a dynamic, changing concept in constant evolution. From the days of ancient Greek and Roman societies to our days, the family has grown, adapted, and also (almost symbiotically) contributed to very remarkable social and cultural changes for society. In Colombia, these changes were anticipated and investigated by anthropologist Virginia Gutiérrez, and have become dramatically notorious since the Colombian Constitution of 1991. Only with the birth of the new Political Charter, non-heterosexual persons, single mothers, remarried individuals and those who simply did not marry under the Catholic rite were able to find the legal tools to claim the guarantee of subjective and objective rights which had been historically denied to them, either for political or cultural reasons, or with social and particularly moral pretexts.

Therefore, by means of a literature and documentary reviews in light of the hermeneutical historical method, we shall attempt to first reflect on the relationship between the findings and contributions of anthropologist Virginia Gutiérrez and what has been developed by constitutional jurisprudence since the 1991 Political Charter; and second, we shall endeavor to set out certain contributions regarding the social and cultural challenges and perspectives of the Colombian family in its various forms and typologies.
\end{abstract}

Keywords: Family; adoption; homosexual adoptions; marriage; common law marriage; same-sex marriage; jurisprudence; Anthropology; Virginia Gutiérrez. 


\section{O CONCEITO DE FAMÍLIA NA COLÔMBIA: UMA REFLEXÃO A PARTIR DAS CONTRIBUIÇÕES DA ANTROPÓLOGA VIRGINIA GUTIÉRREZ SOBRE A FAMÍLIA COLOMBIANA NO MARCO DA DOUTRINA CONSTITUCIONAL}

\section{RESUMO:}

A família, como instituição social e cultural, é claramente um conceito dinâmico, mutável, em constante evolução. Desde as antigas sociedades gregas e romanas até os dias atuais, a família cresceu, se adaptou e também -quase simbioticamente- levou a significativas mudanças sociais e culturais para a sociedade. Na Colômbia, tais mudanças foram antecipadas e pesquisadas pela antropóloga Virginia Gutiérrez e tornaram-se dramaticamente notórias desde a Constituição de 1991. Com o nascimento da nova Carta Política, as pessoas não heterossexuais, as mães chefes de família, os indivíduos em segunda união ou simplesmente aqueles que não casaram sob o rito católico encontraram as ferramentas legais para reivindicar a garantia de direitos subjetivos e objetivos que, historicamente, foram-lhes desconhecidos por razões políticas e culturais ou por preconceitos sociais e especialmente morais.

Assim, através de uma revisão bibliográfica e documental à luz do método hermenêutico histórico, pretende-se inicialmente refletir sobre a relação entre as descobertas e contribuições da antropóloga Virginia Gutiérrez e o desenvolvimento da jurisprudência constitucional baseada na Carta Política de 1991 e, num segundo momento da mesma maneira, procura-se levantar algumas contribuições sobre os desafios e perspectivas sociais e culturais da família colombiana em suas diferentes formas e tipologias.

Palavras-chave: Família, adoção, adoção homosexual, casamento, união estável, casamento igualitário, jurisprudencia, Antropologia, Virginia Gutiérrez.

\section{INTRODUCCIÓN}

La familia en Colombia ha sido quizás la institución más afectada y maltratada por numerosos factores internos y externos, factores, en su mayoría, fruto de construcciones culturales hegemónicas que, de un modo u otro, han influido en la formación de nuestro sistema social. Tanto el mito de la superioridad masculina y la consiguiente infalibilidad del sistema patriarcal $^{1}$ como el discutible rol de sumisión de la mujer, son ejemplos

1 Ximena Pachón define el "patriarcalismo" o "autocratismo masculino" como un sistema caracterizado por una relación dispar hombre-mujer en el manejo de la autoridad, el poder y las decisiones, sesgada siempre en favor del primero. De esta manera, la posición masculina prevalente emana y se expresa en un estatus adscrito por género y luego en el ejercicio por género y luego en el ejercicio de posiciones adquiridas privativas de su sexo y rodeadas al 
de conceptos que si bien han sido replanteados en algún momento, continúan conservando un importante y desafortunado peso en el devenir de la sociedad colombiana, tal y como lo podemos ver a través de lo manifestado por la Corte Constitucional tan solo hasta el 2006²:

El respeto por la dignidad humana exige reconocer en las mujeres igual dignidad a la que durante mucho tiempo solo se reconoció en los hombres. Requiere que las mujeres sean tratadas con el mismo respeto y consideración con que son tratados los varones. Lo anterior no como resultado de un acto de liberalidad o condescendencia sino porque las mujeres por sí mismas son reconocidas como personas y ciudadanas titulares de derechos cuya garantía está amparada en forma reforzada por los ordenamientos jurídicos interno e internacional. El respeto por la dignidad humana de las mujeres significa, además, dejar de considerarlas "objeto" a disposición de los hombres: padres, maridos o compañeros permanentes. Este reconocimiento expreso en el texto constitucional constituye sin duda un paso enorme, ante todo cuando se piensa que la entidad de persona y de ciudadanas de las mujeres fue puesta en duda por siglos, y será profundizado por lo dispuesto en la Constitución vista en su conjunto y, en particular, por lo preceptuado en los artículos 13, 40 y 43 superiores. (Sentencia C-804/2006)

Dado lo anterior, y en búsqueda de un espacio de reflexión bajo la luz del trabajo de la antropóloga Virginia Gutiérrez, se considera oportuno analizar los aportes brindados por Gutiérrez quien, en palabras de Ximena Pachón (2009):

Incursionó directamente en lo que podríamos llamar historia de la familia al plantearse como objetivo el recobrar las realidades de épocas pasadas mediante el uso de testimonios escritos... y sus análisis sobre la familia del siglo mediante la utilización de métodos eminentemente antropológicos o sociológicos. (p. 249)

Así las cosas, al reflexionar sobre el trabajo desarrollado por la antropóloga colombiana sobre la familia en Colombia y sus diferentes formas de evolucionar durante el siglo XX, podemos encontrarnos con dos importantes ideas: en primer lugar, hallaremos los elementos que nos brinda su obra para comprender el desarrollo histórico de la institución familiar en Colombia; en segundo lugar, y más importante aún, reflexionaremos sobre los retos de la institución familiar colombiana en el siglo XXI.

Recordemos que la antropóloga colombiana, quien a pesar de haber sido opacada por la indiferencia de autores masculinos de su época, ha

prestigio diferencial frente a la mujer. (Pachón, 2009, p. 263)

2 Corte Constitucional, Sentencia C-804 de 2006.Magistrado Ponente Humberto Antonio Sierra Porto. 
construido importantes aportes al servicio de las ciencias humanas, especialmente en lo referente a la familia en Colombia, sus tipologías, su formación, su evolución y sus rasgos característicos de acuerdo con las diferentes regiones geográficas del país.

El trabajo sobre la familia desarrollado por Virginia Gutiérrez encuentra su génesis en donde terminaron otros. A mediados del siglo XX la concepción general en los medios académicos de la sociología y la antropología era que "la familia colombiana" consistía en el constructo social y eclesiásticamente aceptado de padre, madre e hijos (Vila de Pineda, 2002), y que cualquier tipología familiar debería adaptarse a la definición impuesta; sin embargo, decide emprender sus trabajos convencida de la fuerte influencia de la familia sobre problemáticas como "...la nutrición, el desarrollo y los traumas de la personalidad, la dinámica de las clases sociales, el analfabetismo, el control de la enfermedad, el alcoholismo, la prostitución, la interrelación de los individuos y de los grupos y el homosexualismo..." (Gutiérrez de Pineda, 1964, p. 11).

Uno de los principales aportes de la antropóloga santandereana se ve plasmado en su obra de $1968^{3}$; claramente, el propósito de la mencionada obra, considerada una continuación de su anterior libro, era presentar una descripción de la tipología y estructura familiar colombiana de mediados del siglo XX. Es en el contexto del desarrollo de este trabajo que nace un hecho que dio un importante giro a la forma como las Ciencias Sociales percibían el país, tal hecho fue, como lo narra Ximena Pachón (2008, p.259), el establecimiento de lo que Gutiérrez llamaría "Complejos Culturales" o "Subculturas" para explicar que ..."el país se repartía en zonas configuradas bajo indicadores peculiares en cada una, de cuyo funcionalismo la institución de la familia venía a ser solo un fragmento, una secuencia o una implicación causal". Esta definición permite a la antropóloga establecer los siguientes complejos culturales referidos a las realidades geográficas y étnicas, a saber: complejo andino, complejo santandereano, complejo antioqueño y complejo negroide. Nos encontramos entonces con uno de los aportes más significativos de Virginia Gutiérrez a las ciencias sociales en Colombia y Latinoamérica, pues desde la publicación del segundo libro sobre la familia, ya no se habla en Colombia de "tipos regionales" sino de "Complejos Culturales", de esta forma, hacen su aparición "...las imágenes paradigmáticas regionales, ya no solo las masculinas, sino también las femeninas, permitiendo que la mujer saliera del olvido y la penumbra de donde las Ciencias Sociales no la habían podido rescatar". (Pachón, 2008, p. 260).

3 Familia y Cultura en Colombia. Tipologías Funciones y Dinámica de la Familia. Manifestaciones Múltiples a través del mosaico cultural y sus estructuras sociales. Coediciones Tercer Mundo y Departamento de Sociología de la Universidad Nacional de Colombia. 
Posteriormente, para el año de 1973 se publica "Estructura, función y cambio de la familia en Colombia”, editado por la Asociación Colombiana de Facultades de Medicina, a través de este trabajo, de línea claramente sociológica

Doña Virginia analiza el papel de las relaciones de género dentro de la familia y la sociedad de manera tan sistemática y creativa que los especialistas lo consideran un verdadero tratado sobre la comunicación familiar, en el cual se indagan temas referentes a asuntos fundamentales tanto para la familia, como célula básica de la sociedad, como para el individuo en particular. En su análisis surgen los sentimientos, las obligaciones, las situaciones traumáticas, la socialización de los miembros, la religión y muchos otros temas. Se estudia el paso de los complejos culturales a formas urbanas mixtas, se explicita su rompimiento cuando empiezan a mezclarse en las ciudades parejas que traen bagajes culturales disímiles y cuyos cónyuges se encuentran en proceso de adaptación a un medio citadino más agresivo. Se analiza el paso de la familia extensa rural a la nuclear urbana, se encuentra el origen del individualismo, característico de la familia citadina, cuando en las urbes las familias tienen que responder por ellas mismas y donde ya no hay cabida para brindar apoyo a los distintos miembros de la extensa parentela rural (Vila de Pineda, 2002, p. 246).

Ya para el año de 1988, la comunidad académica recibe un libro escrito por Virginia Gutiérrez con su nuera, la también antropóloga Patricia Vila de Pineda. Este trabajo lleva por título "Honor, Familia y Sociedad en la estructura patriarcal, el caso de Santander". Este estudio sobre el patriarcalismo lo referencia Ximena Pachón (2008, p. 262 - 263) como un análisis regional enfocado sobre la familia patriarcal en el departamento de Santander, con el cual se propone mostrar los rasgos característicos de este sistema de autoridad, que son comunes en todo el país porque teniendo sus raíces históricas en la colonia y habiendo mantenido sus componentes básicos, prácticamente intactos, ha llegado a integrarse estructuralmente en las instituciones, encontrando su respaldo en la cultura.

Ahora bien, la observación de la familia colombiana por parte de Gutiérrez no se detuvo, por el contrario continuó estudiando su evolución y, naturalmente, comunicando sus hallazgos principalmente como conferencista. Es interesante encontrar que uno de los aportes de sus últimos años de vida fue explicar el fenómeno de la "familia padrastral" como fruto de las separaciones sucesivas y la reincidencia en nuevas uniones. La antropóloga -que a la sazón estaba por los 71 años- explicaba que mientras en las uniones estables las relaciones de parentesco son bilaterales

...en las nuevas formas llega a ser multilateral y a crear un lazo fraternal nuevo entre descendientes de una pareja, cada uno de cuyos integrantes ha tenido más de una unión, y algunos de cuyos hijos, separadamente, 
no tienen parentesco entre sí. (Gutiérrez de Pineda, 1993; citado por Pachón, 2008, p. 265).

Sin embargo, es necesario resaltar que la familia padrastral no fue la única forma de familia encontrada en la segunda mitad del siglo XX; Virginia Gutiérrez también estudió y expuso el desmonte

del modelo tradicional basado en el patriarcalismo y el aparecimiento de una morfología familiar múltiple y contradictoria asociada con las exigencias de la modernidad. Habló de la familia superpuesta y de la revitalización o retorno de la familia extensa que se había visto retroceder en el transcurso del siglo XX. Explicó cómo la familia extensa volvía a ser funcional ante las múltiples rupturas de las uniones de la generación filial, cuando la mayoría de las hijas separadas regresan a su "hogar de orientación", donde bajo el amparo y tutela de los abuelos encuentran el apoyo y protección que perdieron al romperse la unión con el compañero. Habló también de las familias de homosexuales y lesbianas, de los triángulos familiares de una pareja... y de las múltiples versiones de las uniones de facto... (Gutiérrez de Pineda, 1992; citado por Pachón, 2008, p. 265)

\section{UN POCO DE HISTORIA}

Con el ánimo de dar respuesta al interrogante que convoca el desarrollo del presente trabajo es imperativo repasar, brevemente, el origen del concepto de familia, y de este modo, acercarnos más a la importancia y al significado no solo del término sino de la institución de la familia como núcleo social básico.

El concepto de familia organizada, al menos para las sociedades occidentales, se puede encontrar en la antigüedad, en las estructuras griegas y romanas, las cuales coinciden en más de lo que solemos imaginar, ya que el concepto de familia va muy ligado a la religión, la religión familiar. La unión entre miembros de una misma familia no nace exclusivamente de la generación, tampoco consiste en el afecto natural ya que "el derecho griego y el derecho romano no tienen en cuenta para nada ese sentimiento" (Fustel de Coulanges, 1997, p. 35); el factor que cohesiona fuertemente a una familia antigua es el concepto de la religión familiar, "lo que une a los miembros de la familia antigua es algo más poderoso que el nacimiento, que el sentimiento, que la fuerza física; es la religión del hogar y los antepasados." (Fustel de Coulanges, 1997, p. 35).

Esta noción de religión doméstica o religión del hogar, tanto en Grecia como en Roma, nos muestra que la familia no solo es una asociación natural, es una asociación social-religiosa que debe prevalecer en el tiempo. El griego y el romano antiguo no concebían que al final de su existencia no existiera un descendiente que prolongara la responsabilidad familiar de los ritos religiosos. De tal suerte que se conformaba y se fortalecía con el pasar de los siglos la responsabilidad del hombre como jefe de familia 
en el mantenimiento del hogar: la religión doméstica le exigía tener un altar en determinada parte de su casa para honrar a sus dioses y antepasados y, de igual forma, honrar a los muertos con ritos fúnebres precisos, constantes y cíclicos. (Fustel de Coulanges, 1997, p. 31-32)

De esta forma se determinan las responsabilidades, las necesidades y las interacciones de la antigua familia griega y romana, las que se identifican con constructos conceptuales nacidos de la religiosidad y que a través de los siglos se fueron adaptando a los usos civiles, jurídicos y políticos de las instituciones tanto griegas como romanas, sobreviviendo a la caída del imperio romano y encontrando un nicho más que adecuado con el naciente cristianismo, de modo que durante la Edad Media los conceptos de familia, patriarcado, papel de la mujer y sumisión de la mujer, solamente fueran reforzados a través de las diversas prácticas sociales y religiosas que identificaron los casi 10 siglos de duración de la Edad Media.

El tema en el "nuevo mundo" no fue distinto, todos los conceptos de familia fortalecidos en la Edad Media en Europa fueron impuestos por la colonización española y, en mayor o menor grado, promocionados tanto por la iglesia católica como por las autoridades jurídicas de la época. (Molina y Rodríguez, 2014)

Tal realidad se mantuvo históricamente casi hasta finales del siglo XX, lo que significa una fuerte influencia en la sociedad y su mentalidad. La familia se define, entonces, como el núcleo básico de la sociedad y se compone de padre, madre e hijos, donde el padre funge como proveedor y protector, en tanto que la mujer cría a los hijos y estos a su vez se supeditan a la autoridad de los progenitores. Todo lo anterior perfectamente alineado con las normas sociales y religiosas que identificaban la moral colectiva de un país como Colombia.

Sin embargo, aparece en la escena colombiana la antropóloga colombiana Virginia Gutiérrez (1922-1999), quien a pesar de haber sido opacada por autores masculinos de su época ${ }^{4}$, construyó aportes importantes para las ciencias humanas, especialmente en lo referente a la familia en Colombia y su evolución. Como lo describe Rueda Enciso en su reseña publicada en línea ${ }^{5}$ en septiembre de 2016:

Virginia Gutiérrez se dedicó al estudio de la familia y la cultura en Colombia, para lo que -a partir de la década de 1950- adelantó diversos

4 Virginia Gutiérrez de Pineda: ve lo que todos han visto pero piensa lo que otros no han pensado. Artículo de Ligia Echeverry Ángel, socióloga y antropóloga de la Universidad Nacional de Colombia.

5 Artículo VIRGINIA GUTIÉRREZ DE PINEDA: INVESTIGADORA DE FAMILIA Y CULTURA EN COLOMBIA. Recuperado de: http://www.revistacredencial.com/ credencial/historia/temas/virginia-gutierrez-de-pineda-investigadora-de-familia-y-culturaen-colombia 
estudios históricos, etnográficos, entre otros, y que dieron fruto a ocho libros, siendo particularmente importante Familia y cultura en Colombia (1968, con reediciones en 1975 y 1993), en el que presenta una amplia y extensa caracterización de la tipología y estructura colombiana, mediante cuatro complejos culturales o subculturas: complejo cultural andino, complejo santandereano, complejo antioqueño y complejo litoral-fluvio-minero; con ello le dio un nueva dimensión a lo regional y aportó elementos inéditos para comprender la evolución de la economía y sociedad colombiana durante los dos últimos siglos. Con la virtud de que, además de suministrar un andamiaje teórico importante, ha podido hacer inferencias y conjeturas prácticas, como las que trabajó en su libro Honor, familia y sociedad, el patriarcalismo en Santander.

De tal forma que el presente trabajo constituye una propuesta de punto de partida para preguntarnos sobre la evolución de la familia en Colombia y sobre el papel e influencia de esta institución como factor de cambio en nuestra sociedad del siglo XXI.

\section{HIPÓTESIS}

Como lo hemos visto a través de Fustel de Coulanges (1997, p 31-35) la familia antigua (Grecia y Roma) era una asociación social-religiosa que debía prevalecer en el tiempo, con el fin de conservar la responsabilidad familiar religiosa, toda vez que la religión doméstica le exigía tener un altar en determinada parte de su casa para honrar a sus dioses y antepasados y, de igual forma, rendir honores a sus muertos con ritos fúnebres precisos, constantes y cíclicos. De manera que, como lo señala precisamente el historiador francés (1997, p. 45-50), el principio de la familia antigua no radica exclusivamente en la procreación, esto se demuestra, por ejemplo, en que la hermana no es en la familia lo que es el hermano. Así mismo, no se considera como tal al hijo emancipado o a la hija casada.

Esta era la manera como se establecían las responsabilidades, las necesidades y las interacciones de la familia antigua griega y romana; tales constructos nacidos de la religiosidad, que a través de los siglos se fueron adaptando a los usos civiles, jurídicos y políticos de las instituciones tanto griegas como romanas a través de las cuales se entiende que ni el hecho biológico del nacimiento ni la afectividad (como la entendemos actualmente) fueron el fundamento de la antigua familia romana y griega; como tampoco el poder masculino por la mera fuerza. La autoridad paternal o marital no ha sido la génesis de la religión familiar de la familia antigua, por el contrario, ha sido la consecuencia. Ya hemos visto que la religión doméstica necesita de la familia y esta, a su vez, va estableciendo -más por costumbre y necesidad práctica- los roles y las relaciones de poder entre sus miembros. ${ }^{6}$

6 En el Capítulo VII de su obra LA CIUDAD ANTIGUA, Fustel de Coulanges señala: "La ley que permite al padre vender y aún matar al hijo, ley que encontramos en Grecia como 
$\mathrm{Al}$ caer el imperio romano $\mathrm{y}^{7}$ surgir el fortalecimiento del cristianismo las creencias, costumbres y leyes romanas referentes a la familia y los roles de sus integrantes no desaparecieron, por el contrario, se fortalecieron, algunas adaptándose a lo exigido por la religiosidad cristiana y otras tantas constituyendo pilares de esas mismas creencias, de modo que durante el Medioevo los conceptos de familia, patriarcado, papel de la mujer y sumisión de la mujer, resultaran casi que exclusivamente reforzados a través de las diversas prácticas sociales y religiosas que identificaron a las sociedades estamentales medievales.

Ahora bien, la colonización de América permitiría las condiciones ideales para el crecimiento de los conceptos de familia fortalecidos en la Europa medieval, impuestos por el invasor y, en mayor o menor grado, promocionados tanto por la iglesia católica como por las autoridades jurídicas y judiciales de la época, como lo refieren acertadamente las profesoras Nathaly Rodríguez y Diana Molina:

El honor es un concepto cargado de significaciones simbólicas llegadas a

en Roma, no la ha concedido la ciudad... El derecho privado era anterior a ella (la ciudad). Cuando empezó a escribir sus leyes encontró ya establecido este derecho, vivo, arraigado en las costumbres, fuerte con la adhesión universal. Lo aceptó, no pudiendo hacer otra cosa, y solo a la larga osó modificarlo. El derecho antiguo no era obra de un legislador; al contrario, se ha impuesto al legislador. Es en la familia donde ha encontrado su origen. Ha surgido espontáneo y bien formado de los antiguos principios que lo constituían. Se ha derivado de las creencias religiosas que estaban universalmente admitidas en la primitiva edad de estos pueblos y que ejercían imperio sobre las inteligencias y sobre las voluntades".

7 El Imperio Romano alcanzó su mayor extensión al comienzo del siglo II d. C y duró 2.000 años. Estaba dividido en provincias, directamente sometidas al control del Emperador y del Senado. A pesar de que en esta época alcanzó su máximo esplendor, existían algunos problemas graves que se fueron ahondando a partir del siglo III d. C. Estos fueron: Enemigos externos: Aparecen pueblos que amenazan las fronteras romanas, especialmente los persas en la zona de Mesopotamia y los germanos en el Rin. Excesivo poder de los soldados: El peligro inminente de los pueblos germanos en la frontera noreste obligó a Roma a mantener en armas un ejército de medio millón de legionarios quienes comenzaron a usar la fuerza para nombrar a los emperadores que les prometían favorecerlos. Esto provocó una gran inestabilidad política. Gran crisis social: Esta crisis se manifestó principalmente en las provincias más atrasadas del Imperio, cuyos habitantes le exigieron al gobierno la totalidad de los derechos políticos y sociales. Ruptura del equilibrio económico: El sector de Oriente del Imperio se enriqueció más que el sector Occidental, lo cual provocó problemas dentro del Imperio. Gran crisis económica: Se elevaron los impuestos y contribuciones. Se ensayó la planificación central y rigurosa de la producción pero solo provocó el estancamiento generalizado. Aparecen la inflación y el desempleo, el desabastecimiento, el mercado negro y la especulación. Gran concentración urbana y éxodo rural: Los habitantes del Imperio dejan las zonas rurales y se dirigen hacia las ciudades.

El quiebre definitivo se produjo cuando Teodosio, emperador de origen español, legó el Imperio Romano, al morir, a sus dos hijos. Honorio le correspondió el Imperio de Occidente, cuya capital era Roma, y a su segundo hijo, Arcadio, el Imperio de Oriente, cuya capital era Constantinopla, siguiendo destinos muy diferentes. En el año 476 después de Cristo, el Imperio Romano de Occidente sucumbía bajo la presión de los germanos, mientras que el Imperio Romano de Oriente sobrevivió hasta el año 1453 después de Cristo, año en que cayó en poder de los turcos. Es propiedad: www.profesorenlinea.cl. Registro No 188.540 
América Latina por la influencia hispánica, cuyo valor y guarda eran vitales para la identidad y el reconocimiento de cada individuo que lo portaba y que lo depositaba en su cónyuge e hijas. Su especial protección implicó practicas judiciales presentes en las instituciones de Hispanoamérica hasta muy entrado el siglo XX, de acuerdo con concepciones culturales de posesión y poder sostenidas en el tiempo bajo la representación de familia con roles e imposiciones severos sobre la mujer, depositaria por excelencia del honor masculino. La custodia sobre los cuerpos femeninos y con ello la conservación del honor familiar bajo este orden de significaciones, imprimieron en Colombia prácticas institucionales que luego lo constituyeron en sí mismo en un bien jurídico tutelado por el Estado. (Molina y Rodríguez, 2014, p. 2)

Empero, a la luz de los hallazgos de la antropóloga colombiana Virginia Gutiérrez (1922-1999) se ha encontrado que en lo referente a la familia en Colombia, sus tipologías, su formación, su evolución y sus rasgos característicos de acuerdo a las diferentes regiones geográficas del país, hay mucho más que decir que lo que se había dicho hasta finales del siglo $\mathrm{XX}$, dado que desde la sociología y la antropología se encontró que el concepto de familia va mucho más allá de la noción de familia nuclear según el binomio padre - madre (por fuerza heterosexual) e hijos; existen y existirán otras formas de constituir familia, basadas en realidades socio culturales, en lazos de afectividad y solidaridad, en toda suerte de decisiones personales e individuales.

\section{EL PAPEL DE LA FAMilia COLOMbianA EN EL SIGLO XXI}

Claramente, el desarrollo de los grupos humanos y sus procesos de cambio, tanto sociales como económicos, se han constituido como parte de la génesis de la evolución de la estructura familiar, incidiendo en la aparición de características y, si se quiere, rasgos que nos permiten identificar varios modelos de núcleo familiar, ya que los fenómenos de cambio familiar son resultado de su acomodación a las transformaciones de la sociedad y de la cultura que conforman su estudio (Umaña Luna, 2004; citado por Millán, 2013, p.109).

En Colombia se presentan, específicamente, diversos tipos o formas de familia, es importante resaltar que este fenómeno varía dependiendo de la región geográfica y de los constructos culturales propios como la religiosidad, la mayor o menor "pureza" de las costumbres, el contacto con los medios masivos de comunicación; de igual forma, inciden en las formas de familia, tanto el estrato social, los antecedentes étnicos y la historia como tal.

Actualmente, como se puede notar en el trabajo de la antropóloga Virginia Gutiérrez, los cambios reflejados en la familia desde la segunda mitad del siglo XX evidencia un ambiente de crisis que puede tomarse ya sea 
como generador de una inestabilidad institucional, ya sea como el espacio para el nacimiento de nuevas normativas, nuevos roles y, por supuesto, nuevos límites. Al tenor de lo anterior, la Abogada Carmen Millán señala:

La familia nuclear, que durante varias décadas fue un modelo normativo en la sociedad, es actualmente, solo una de las tantas posibilidades de familia. Las nuevas formas familiares generan nuevas necesidades a las que la política pública debe responder, y seguramente también estas nuevas formas transforman aspectos importantes, tales como la salud, por ejemplo. (Millán, 2013, p, 108).

Así las cosas, es clara la influencia de los cambios en la familia colombiana y en las relaciones, tanto al interior de ella como hacia el exterior de sus límites, de manera que la familia en Colombia, cualquiera que sea su forma, se encuentra llamada a proponer profundas reflexiones frente a sus problemáticas, con el fin de retomar el papel de apoyo y orientación integral a sus miembros, en especial a los menores de edad.

Precisamente el núcleo familiar, cualquiera que sea la forma de este, constituye no solo la génesis de la formación de un individuo, sino que también es un elemento necesario dentro de la dinámica de la sociedad moderna, es por esto que el concepto de familia ha sido motivación para que la Corte Constitucional establezca importantes parámetros de defensa y protección de derechos constitucionales relacionados con la familia. Un ejemplo de lo anterior se encuentra en el marco conceptual dado por la Corte Constitucional a través de sentencia de Tutela T-070 de 2015:

La Constitución Política de Colombia, establece en su artículo 42, que la familia puede constituirse por medio de vínculos naturales o jurídicos, mediante la determinación de dos personas de contraer matrimonio o por la voluntad libre y responsable de conformarla. Así mismo, la Carta Política señala que dicha institución, es el núcleo básico de la sociedad, por lo que el Estado y la Sociedad, deben garantizar su protección integral, de acuerdo con lo establecido en el artículo $5^{\circ}$ Superior. Igualmente, el artículo 42 Constitucional señala que "los hijos habidos en el matrimonio o fuera de él, adoptados o procreados naturalmente o con asistencia científica, tienen iguales derechos y deberes", extendiendo de esta manera el principio de igualdad al núcleo familiar. Dicha igualdad, exige que se trate con similar respeto y protección a todos los tipos de familia, prohibiendo todo tipo de discriminación, ya sea contra los hijos o contra cualquier descendiente, sin importar el grado. (Corte Constitucional, 2015, Sentencia T-070)

Asimismo, en el año 2013, la Corte Constitucional manifestaba a través de sentencia de Tutela T-606 de 2013, lo siguiente sobre la protección de los diversos tipos de familia: 
De acuerdo con el artículo 42 de la Constitución Política, la familia puede conformarse por matrimonio o por la voluntad responsable de conformarla, y el Estado y la sociedad deben garantizar su protección integral. También señala el artículo en comento que "Los hijos habidos en el matrimonio o fuera de él, adoptados o procreados naturalmente o con asistencia científica, tienen iguales derechos y deberes.", proyectando de esta forma el principio de igualdad al núcleo familiar. Esta última consideración en relación con los hijos, cobra especial relevancia cuando se trata de analizar familias conformadas por los hijos procreados por la pareja y los habidos fuera del matrimonio o de la unión marital de hecho. (Corte Constitucional, 2013, sentencia T-606)

Consideramos que sin los aportes sociológicos y antropológicos de Virginia Gutiérrez quizás el camino de la familia en Colombia como institución cambiante y dinámica hubiere sido mucho más difícil, escabroso y complicado.

Curiosamente, después de la proclamación del texto constitucional de 1991, el reconocimiento y la construcción de los derechos de los integrantes de las nuevas tipologías de familia que logró anticipar muy acertadamente Virginia Gutiérrez no se ha dado por vía legislativa -que habría sido lo medianamente lógico en un Estado Social de Derecho- sino por vía jurisprudencial y especialmente de jurisprudencia constitucional.

En este punto es necesario traer a colación lo encontrado por Virginia Gutiérrez (1996), quien describía a la familia tradicional colombiana a través de varias características básicas frente a las cuales la antropóloga encuentra los contrastes que han marcado la evolución del concepto de familia a partir de la sexta década del siglo XX, entre otras cosas a raíz de los cambios sociales y económicos acaecidos en la sociedad colombiana, el paso de una sociedad rural a una urbana industrial, ampliación de oportunidades de empleo y educación para la mujer, la pérdida de influencia de la Iglesia Católica, entre otros.

\begin{tabular}{|l|l|}
\hline $\begin{array}{l}\text { Características de la Familia tradi- } \\
\text { cional colombiana - Siglo XX }\end{array}$ & $\begin{array}{l}\text { Avances estructurales - De acuerdo } \\
\text { con los estudios de Virginia Gutié- } \\
\text { rrez }\end{array}$ \\
\hline $\begin{array}{l}\text { Conformación por matrimonio católi- } \\
\text { co. Escasa influencia del civil, las for- } \\
\text { mas de hecho se adscribían a sectores } \\
\text { de los grupos bajos y no encuadran } \\
\text { dentro del modelo. }\end{array}$ & $\begin{array}{l}\text { católico, hay aumento del matrimonio } \\
\text { civil y las formas consensuales.1 }\end{array}$ \\
\hline
\end{tabular}


Estructura patriarcal: el padre era la cabeza social y económica de las familias; la madre y los hijos, miembros dependientes de su autoridad.

El padre decidía y se responsabilizaba; la mujer y los hijos obedecían y ejecutaban.

La residencia era patrilocal.
Cambios en el patriarcalismo: la autoridad masculina pierde su absolutismo, a favor de la equiparación o "sistemas democráticos". Al interior de la familia el ejercicio de la autoridad se apoya ahora en el principio de que todos deciden, todos hacen y todos se responsabilizan.

Neolocalismos: el padre no impone el domicilio conyugal. La residencia de la familia depende de la conveniencia profesional, tanto del esposo como de la esposa, dentro de principios de solución en caso de conflicto.

El matrimonio era indisoluble. Por causales estrictas se admitía la separación, pero no el divorcio.

Legalmente monogámica, con privilegios poligínicos encubiertos al hombre y fidelidad femenina estricta. Al mismo tiempo regía una endogamia de clase, etnia y otras variables.

Separación tajante de roles por género, y prestigio diferencial por su cobertura.

\begin{tabular}{|c|c|}
\hline P= & $\begin{array}{l}\text { neración femenina que entra a ser } \\
\text { coproveedora, y cubre también todos } \\
\text { los roles adscritos tradicionalmente a } \\
\text { su sexo. Esta evolución lleva a que la } \\
\text { mujer asuma papel de proveedora y el } \\
\text { hombre asuma tareas del hogar, con- } \\
\text { certadamente. }\end{array}$ \\
\hline $\begin{array}{l}\text { Territorios adscritos por sexo, sociedad } \\
\text { y cultura para el hombre, y hogar para } \\
\text { la mujer. }\end{array}$ & $\begin{array}{l}\text { Quiebra definitivamente de territorios } \\
\text { por género: El cambio en los roles por } \\
\text { sexo de la familia tradicional abrió la } \\
\text { puerta a la mujer para entrar a la activi- } \\
\text { dad en el complejo institucional global; } \\
\text { el hombre, por cambios internos en la } \\
\text { familia, ha comenzado a compartir las } \\
\text { tareas hogareñas. }\end{array}$ \\
\hline
\end{tabular}

Creciente ruptura familiar que se acentúa en la década de 1960 y que se incentiva más aún en las uniones de hecho y en las generaciones nuevas. 2

Como sumatoria y evolución de las condiciones anteriores ha cambiado la edad para contraer, lo que no significa la negación de la satisfacción sexual. Se incentiva la nupcialidad3 en ambos géneros.

Cambio en la estructura de roles: La transformación se inicia con una generación femenina que entra a ser coproveedora, y cubre también todos os roles adscritos tradicionalmente a su sexo. Esta evolución lleva a que la mujer asuma papel de proveedora y el hombre asuma tareas del hogar, con- 


\begin{tabular}{|l|l|}
\hline $\begin{array}{l}\text { Vida erótico-afectiva normatizada se- } \\
\text { gún principios patriarcales. Procrea- } \\
\text { ción no controlada. }\end{array}$ & $\begin{array}{l}\text { Las relaciones erótico-afectivas han } \\
\text { presentado profundos cambios. Desta- } \\
\text { ca la dualización de la relación sexual } \\
\text { en gratificante y procreativa. La pri- } \\
\text { mera se impone a la segunda que se } \\
\text { transforma en planeada o consciente, } \\
\text { limitada o eliminada voluntariamente. }\end{array}$ \\
\hline $\begin{array}{l}\text { Valores fuertemente interiorizados de de } \\
\text { compromiso obligatorio. }\end{array}$ & $\begin{array}{l}\text { Inestabilidad matrimonial, altos índi- } \\
\text { ces de ruptura doméstica. }\end{array}$ \\
\hline
\end{tabular}

Tabla No. 1. Construcción propia, basada en el documento de Gutiérrez de Pineda (2005). Modalidades familiares de fin de siglo. En Maguare. Huellas Escritas. Recuperado de http://www.revistas.unal.edu.co/index.php/ maguare/article/view/10774. Universidad Nacional de Colombia, Bogotá.

Es interesante ver cómo partiendo de esta evolución social han ido surgiendo nuevas tipologías familiares (Gutiérrez, 2005), que en algunos casos resultan difíciles de entender y asimilar, y es que -por ejemplo- hasta el momento los censos oficiales omiten ${ }^{8}$ las modalidades diferentes a las formas matrimoniales y de Unión Marital de Hecho (UMH). Empero, es necesario aclarar que las tipologías de familia de las que nos habla la antropóloga santandereana no son realidades desconocidas entre la sociedad colombiana, sino que son, de alguna forma, más o menos encubiertas o invisibilizadas; existían y existen.

De acuerdo con Virginia Gutiérrez (2005), la forma más enculturada dentro del marco del modelo católico pervive la familia monogámica; es decir, la conformada por hombre y mujer a raíz del matrimonio (sea religioso o civil). La segunda forma, también con arreglo al concepto de monogamia, la constituye la Unión Marital de Hecho, constituida por uniones de solteros, aunque con ruptura matrimonial creciente, o también uniones de casados con matrimonios en quiebra (Gutiérrez, 2005). También relaciona Gutiérrez de Pineda la familia superpuesta para referirse a la unión nacida de la ruptura de un matrimonio católico sin opciones de divorcio y reestructurado conyugalmente a través de matrimonio civil o de UMH.

No obstante, y más relacionado con el propósito de este estudio, se encuentra que, dentro de la constelación de uniones y sus variables documentadas por Virginia Gutiérrez, aparecen las uniones de satisfacción erótica-afectiva (Gutiérrez, 2005), tipologías que cuestionan el paradigma tradicional de que la familia lleva implícita la obligación de reproducir la especie.

Tales tipologías se presentan, según Gutiérrez de Pineda (2015), en dos grandes grupos: el primero, las parejas heterosexuales compuestas por

8 Ver: https://www.youtube.com/watch?v=4JiaUpaMowg y https://www.youtube.com/ watch? $v=c c 4 v M J c J f q M \& v l=e s$ 
solteros o separados quienes no necesariamente deben tener unidad habitacional ni financiera. El segundo grupo lo conforman las uniones de homosexuales que implican la carencia de funciones reproductivas, pero que se caracterizan por vínculos de afecto, solidaridad y gratificación sexual; algunas de estas parejas homosexuales educan hijos, bien porque alguno de los integrantes es bisexual y conserva sus hijos, o bien porque acogen infantes en calidad de hijos de crianza (Gutiérrez, 2005), o más recientemente en adopción (López, 2016).

Ahora bien, frente a la realidad descrita anteriormente, la Corte Constitucional ha tenido que entrar algunas veces a interpretar y, en otros casos, a garantizar y proteger los derechos de grupos minoritarios que participan activamente de la conformación de tipologías familiares diferentes a la tradicional. Con la intención de explicar lo anterior se presentan a continuación algunos de estos casos.

El caso Chandler Burr (Sentencia de Tutela T-276 de 2012) reflejó una de las primeras situaciones conocidas y resueltas por la Corte Constitucional en el tema de la adopción, aunque en su sentencia no se pronunció sobre el tema de igualdad, como tampoco estaba encaminada a resolver la controversia sobre si las parejas del mismo sexo pueden adoptar; sin embargo, es necesario resaltar que la Sala Séptima de Revisión de Tutela de la Corte Constitucional tuteló el derecho al debido proceso de un hombre soltero homosexual y los derechos de sus hijos adoptivos a ser oídos y a no ser separados de su padre de forma injustificada, después de que el INSTITUTO COLOMBIANO DE BIENESTAR FAMILIAR - ICBF iniciara un proceso de restablecimiento de derechos y separara a los niños del padre, sin que existiera evidencia de que los derechos de los niños estuvieran siendo vulnerados o se hallaran bajo alguna amenaza, de tal suerte que esta acción de Amparo Constitucional buscaba que cesara el nuevo proceso de restablecimiento de derechos y se devolvieran los niños al padre adoptivo.

La Corte ordenó la devolución inmediata de los niños y la terminación del proceso de restablecimiento, después de declarar que existió una vía de hecho administrativa en la actuación del INSTITUTO COLOMBIANO DE BIENESTAR FAMILIAR - ICBF por dos razones principales: no existía ningún fundamento para la apertura del proceso, y en caso de que hubiera existido, la medida de ubicación en hogar sustituto, en todo caso, era desproporcionada (muy drástica). En este orden de ideas, la sentencia tutela los derechos al debido proceso y los derechos de los niños a ser oídos y a la unidad familiar.

Otro ejemplo han sido las discusiones o "campos de batalla" (López, 2016) que surgieron por cuenta de la Ley 54 de 1990, en la que se estableció el régimen legal para las parejas no conformadas matrimonialmente, a las que se denominó “Unión Marital de Hecho” (UMH), dicho régimen se 
constituía restringido para las parejas conformadas por hombre y mujer, es decir, las uniones que se consideraban "normales".

La Ley 54 de 1990, como lo refiere Diego López (2016, p. 57) estableció explícitamente que la UMH se reconocería a parejas formadas por un hombre y una mujer. A la altura de 1990 esta definición de la pareja parecía natural hasta el punto en que el artículo no se leía como una exclusión de otros tipos posibles de pareja, sino más bien como una pieza de legislación valiente de protección de la mujer concubina en un país tradicionalmente católico que aún tenía serias objeciones ante tal comportamiento, incluso en su versión heterosexual. En 1990, la UMH todavía constituía un reconocimiento bastante agresivo al dar protección legal al patrimonio de compañeros permanentes en detrimento de la pareja formalmente formada en el rito matrimonial (religioso o civil).

Sin embargo, pasado poco tiempo, la ley 54 de 1990 se tornaría estrecha y excluyente (López, 2016) ya que las uniones entre homosexuales, al no tener tampoco una opción de acceder al matrimonio, empezarían a deprecar una regulación de sus efectos patrimoniales y personales a la luz de la ley hasta llegar ante la Corte Constitucional, la cual en 2007, a través de sentencia de Constitucionalidad ${ }^{9}$ revisó por segunda vez la Ley 54 de $1990^{10}$ y declaró exequibles de forma condicionada los artículos 1 y 2 de la Ley 54 de 1990, en el entendido que el régimen de protección en ella contenido se aplica también a las parejas homosexuales (López, 2016).

\section{ALGUNOS EJEMPLOS DE JURISPRUDENCIA DESPUÉS DE 1991}

Uno de los fines del Estado, de acuerdo con la Constitución Nacional de 1991, es procurar la igualdad -al menos ante la ley- de todos los habitantes, en ese orden de ideas, el Estado no puede abstraerse -aunque suele ocurrir- de su responsabilidad de proteger y de garantizar la protección de los derechos y garantías para todos los habitantes del país. La forma como esto se ha hecho evidente en el caso de las parejas homosexuales no ha sido a través de la legislación sino a través de la jurisprudencia de la Corte Constitucional, quizás por alguna "pereza institucional", quizás por temor a juicios moralistas, quizás por temor al castigo de alguna deidad, o quizás un poco de las tres, lo cierto es que gracias a la Corte Constitucional desde hace no muchos años hay por lo menos un referente sobre qué camino seguir con respecto al tema de la protección a la constitución de familias formadas por parejas del mismo sexo en Colombia. Ahora bien, se puede

9 Sentencia C-075 de 2007

10 La primera vez que se revisó esta norma fue en 1996, en donde a través de sentencia C-098 de 1996, determinó que la ley 54 de 1990 no era discriminatoria ni violatoria de derechos fundamentales y además afirmó que la extensión de derechos a la pareja homosexual era constitucionalmente posible; sin embargo, lo anterior dependería de la autonomía del Legislador. 
analizar el desarrollo jurisprudencial frente al tema de las parejas homosexuales desde variados puntos de vista, sin embargo, por razones metodológicas nos vamos a referir específicamente a tres aspectos: el matrimonio, la adopción y los derechos prestacionales, como veremos a continuación.

Así las cosas, en el 2015, la Corte, a través de sentencia de constitucionalidad C-071 de 2015, emite su aprobación de adopción consentida por parejas del mismo sexo cuando el adoptado sea hijo/a biológico/a de uno de los integrantes de la pareja. La demanda presentada ante la Corte tenía como finalidad buscar una interpretación de los artículos 64, 66 y 68 de la Ley 1098 de 2006 (Código de la infancia y la adolescencia) que diera vía libre a la adopción paritaria por parte de las parejas del mismo sexo en el reconocimiento de su derecho a la igualdad (art. 13 C.P) ${ }^{11}$, de los niños a tener una familia y no ser separados de ésta (art. 44 C.P) ${ }^{12}$ y, sobre todo, que en los fundamentos de la Corte se tuviera en cuenta el principio general de la prevalencia del interés superior del niño.

Aunque menos publicitado por los medios, también se demandó el artículo 1 de la Ley 54 de 1990, sobre uniones maritales de hecho que establece que para todos los efectos civiles se denomina "Unión Marital de Hecho" la conformada entre "un hombre y una mujer, que sin estar casados, hacen una comunidad de vida permanente y singular..." (Ley 54 de 1990, Artículo 1) y que se denomina compañero y compañera permanente, "al hombre y la mujer" que forman parte de la unión marital de hecho.

Más recientemente, y proyectada a seguir consecuentemente su línea, la Corte Constitucional manifestó a través de la sentencia C-683 de 2015 que

11 Constitución Política de Colombia, ARTíCULO 13. Todas las personas nacen libres e iguales ante la ley, recibirán la misma protección y trato de las autoridades y gozarán de los mismos derechos, libertades y oportunidades sin ninguna discriminación por razones de sexo, raza, origen nacional o familiar, lengua, religión, opinión política o filosófica. El Estado promoverá las condiciones para que la igualdad sea real y efectiva y adoptará medidas en favor de grupos discriminados o marginados. El Estado protegerá especialmente a aquellas personas que por su condición económica, física o mental, se encuentren en circunstancia de debilidad manifiesta y sancionará los abusos o maltratos que contra ellas se cometan.

12 Constitución Política de Colombia, ARTíCULO 44. Son derechos fundamentales de los niños: la vida, la integridad física, la salud y la seguridad social, la alimentación equilibrada, su nombre y nacionalidad, tener una familia y no ser separados de ella, el cuidado y amor, la educación y la cultura, la recreación y la libre expresión de su opinión. Serán protegidos contra toda forma de abandono, violencia física o moral, secuestro, venta, abuso sexual, explotación laboral o económica y trabajos riesgosos. Gozarán también de los demás derechos consagrados en la Constitución, en las leyes y en los tratados internacionales ratificados por Colombia. La familia, la sociedad y el Estado tienen la obligación de asistir y proteger al niño para garantizar su desarrollo armónico e integral y el ejercicio pleno de sus derechos. Cualquier persona puede exigir de la autoridad competente su cumplimiento y la sanción de los infractores.

Los derechos de los niños prevalecen sobre los derechos de los demás. 
las parejas del mismo sexo pueden acceder al proceso de adopción, lo anterior basado en el concepto de que la orientación sexual de una persona o su sexo no son, por sí solos, indicadores de falta de idoneidad moral, física o mental para adoptar. (Corte Constitucional, Sentencia C-683 de 2015)

Asimismo, en lo tocante al matrimonio, la jurisprudencia es igualmente escasa en número, pero pertinente. La sentencia C-577 de 2011 abrió las puertas para solemnizar la unión gay. El debate jurídico se centró en si la consolidación del vínculo civil entre parejas homosexuales podría o no denominarse matrimonio, con el mismo reconocimiento legal que tiene las parejas heterosexuales, de tal modo que la decisión (seis votos a favor, tres en contra) versa en relación con que los jueces y notarios podrán entender que hay matrimonio para las parejas del mismo sexo. (Ámbito Jurídico, p. 7)

La discusión ha quedado más o menos zanjada por la Sentencia Unificadora SU-214 de 2016:

....La Corte decidió que los principios de la dignidad humana, la libertad individual y la igualdad implican que todo ser humano pueda contraer matrimonio civil, acorde con su orientación sexual. Consideró que celebrar un contrato civil de matrimonio entre parejas del mismo sexo es una manera legítima y válida de materializar los principios y valores constitucionales y una forma de asegurar el goce efectivo del derecho a la dignidad humana, la libertad individual y la igualdad, sin importar cuál sea su orientación sexual o identidad de género" (Corte Constitucional, Sentencia SU-214 de 2016).

En cuanto a los derechos pensionales, las decisiones han sido sobre casos puntuales que se han resuelto en sede de Tutela, es decir, deprecando el amparo de derechos individuales. Algunas sentencias que nos pueden servir como ejemplos son: la sentencia de tutela T-1241 de 2008, la sentencia T-911 de 2009, la sentencia T-357 de 2013 y la sentencia de tutela T-327 de 2014, en las que se tutela el reconocimiento a la pensión de sobreviviente en parejas del mismo sexo, así como la prohibición de pedir pruebas adicionales extralegales que hagan más gravoso el trámite para parejas del mismo sexo.

\section{El punto de inflexión: adopción y matrimonio (C-683/15 y C-577/11)}

A partir del año 1993, la Corte Constitucional se ha venido pronunciando sobre diferentes puntos respecto a los derechos de los grupos LGTBI; sin embargo, se han tomado como hitos las sentencias: C-577 de 2011 (Magistrado Ponente Gabriel Mendoza) y C-683 de 2015 (Magistrado Ponente Jorge Iván Palacio).

Si bien la sentencia C-577 de 2011 abrió las puertas para solemnizar la unión matrimonial en parejas del mismo sexo, también dejó más interro- 
gantes que soluciones en varios aspectos. Aún no se ha pronunciado de fondo acerca de cómo los jueces y notarios deben proceder al momento del vínculo, por otra parte, no se resolvió la controversia sobre si este acto puede catalogarse como matrimonio con los mismos efectos legales de una pareja heterosexual y, adicional a esto, persiste el vacío legal al momento de determinar a qué órgano o ente le compete tomar la decisión definitiva debido a su trascendental importancia, ya que, por un lado, está la Corte Constitucional como salvaguarda de la Carta y, por otro, el Congreso de la República encargado de legislar.

A falta de un pronunciamiento definitivo y debido a las lagunas que dejó el citado fallo, las parejas homoparentales han recurrido a mecanismos jurídicos como la Acción de Tutela con el fin de garantizar sus derechos; lo que ha permitido que no desaparezca el ambiente de discriminación ya existente y, al mismo tiempo, ha fomentado cierta inseguridad jurídica frente al tema. Es importante resaltar que en los casos que hemos mencionado la Corte reconoció que estas parejas pueden conformar familia y que esta se encuentra debidamente protegida por la Carta Nacional; sin embargo, las uniones formalizadas a partir de ese fallo continúan siendo objeto de polémicas y cuestionamientos por parte de sectores conservadores de la sociedad y la política colombiana, como por ejemplo las "marchas por la familia" realizadas en el año $2018^{13}$

13 https://www.eltiempo.com/colombia/cali/marcha-y-contramarcha-por-la-familiatradicional-en-cali-290224. Marcha y contramarcha por la familia tradicional en Cali. En la cabecera de la marcha se leían pancartas como 'La dignidad y la intimidad de la familia son inviolables. Con mis hijos no se metan'. Los participantes apoyan la unión tradicional de hombres y mujeres. Entre los caminantes hay quienes no comparten el aborto. Lina María Herrera, líder en Cali de 40 días por la vida, dijo que es un colectivo que defiende la familia. "Tenemos un hashtag \#nicartillasnidecretos porque no compartimos los decretos que firmó antes de salir el presidente Juan Manuel Santos. Sabemos que esto viene desde la ONU donde están queriendo imponer ideologías contra la familia y la vida. Hace 2 años, en agosto, salimos y nos manifestamos contra las cartillas que manejó la exministra Gina Parody". En los decretos se dispone que se adopten políticas públicas que garanticen el ejercicio efectivo de los derechos de personas de la comunidad LGBTI (lesbianas, gais, bisexuales, transexuales e intersexuales).

https://www.elespectador.com/noticias/bogota/los-temores-detras-de-marcha-familiaarticulo-648506. Los temores detrás de la marcha por la familia. "iRenuncie, renuncie, renuncie!" fueron las primeras palabras que pronunciaron los padres de familia, profesores, activistas y jóvenes que se congregaron frente al Ministerio de Educación, exigiendo la cabeza de la ministra Gina Parody. La razón: la supuesta ideología homosexual que la funcionaria está promoviendo en los colegios. Aunque el argumento demostró el malestar de algunos padres, también reflejó que aún hay desconocimiento sobre la actividad que se adelanta en la reforma a los manuales de convivencia. Sin duda, la desinformación que se generó a través de redes sociales, al atribuirle al Ministerio la autoría de una cartilla con la imagen de una pareja de gais y de un informe elaborado por las Naciones Unidas (en el que aparece el logo del Ministerio de Educación) que habla sobre la importancia de instruir a los jóvenes sobre los temas de género y discriminación, fueron algunos de los factores que detonaron la indignación de los manifestantes (en su mayoría miembros de iglesias cristianas) que ayer marcharon bajo la consigna de proteger la familia en casi todas las ciudades del país. A pesar de que la ministra Parody ha intentado aclarar que ese material 
La segunda sentencia (C-683 de 2015), donde la Corte habilita la adopción de niños por parte de parejas del mismo sexo en virtud del interés superior del menor, el cual le ofrecerá una familia. Aquí, nuevamente, se han suscitado diferentes choques entre diferentes sectores de la sociedad, pero aun así la Corte ha dicho respecto a concepciones científicas y moralistas:

la adopción de niños por personas con orientación sexual diversa, en general, y por parejas del mismo sexo, en particular, no afecta por sí misma el interés superior del menor ni compromete de manera negativa su salud física y mental o su desarrollo armónico e integral. (Sentencia C-683/2015).

A su vez, la corte enfatizó que negar que un menor tenga acceso a una familia sería una restricción inaceptable de sus derechos prevalentes.

A pesar de que la sentencia C-071 de 2015 que le precedió accedió a la adopción de menores por parejas del mismo sexo con la aclaración de que uno de ellos/as sea el/la progenitor/a, la actual concede que estas parejas pueden acceder al proceso de adopción sin delimitación.

De igual forma, a partir del año 2008, por medio de la sentencia C-336, la Corte Constitucional de Colombia reconoció que la regulación sobre la unión marital de hecho también aplicaba para las parejas del mismo sexo y, posteriormente, determinó que la cobertura del sistema de seguridad social en salud del régimen contributivo también admitía la cobertura a

no lo ha promovido su cartera en los colegios y que su tarea se ha limitado a pedir la eliminación de artículos discriminatorios de los manuales de convivencia, "los indignados" siguen convencidos de que bajo su administración los manuales en los colegios se van a regir por una ideología homosexual. Al menos así se expresaba en las pancartas con las que llegaron casi mil ciudadanos hasta las puertas del Ministerio, en las que se leían frases como "No a la educación impositiva de género de nuestros niños y niñas" o se escuchaban opiniones como "Estos temas de discriminación son un invento de la ministra para promover el homosexualismo". En su mayoría, los argumentos se fundamentaban en parágrafos de la Biblia y en el artículo de la Constitución que reduce la conformación de familia a la figura de un hombre y una mujer. A pesar de las protestas, la ministra sigue en su intento por explicar que la única tarea que ha adelantado su cartera es cumplir un fallo de la Corte Constitucional, que se profirió a raíz de la muerte de Sergio Urrego (el joven que se suicidó hace dos años al ser víctima de discriminación en su colegio por su orientación sexual), en el que ordenó revisar los manuales para eliminar los artículos discriminatorios. En medio de esta polémica, Marcela Sánchez, directora de Colombia Diversa, cree que el malestar es más por miedo a la diferencia que un debate con argumentos sólidos. Para ella, lo que realmente le preocupa a la gente que rechaza que se hable de discriminación en los colegios no es siquiera la reforma de los manuales, sino que sus hijos se vuelvan gais o lesbianas, si se permite en los colegios que los niños LGBTI puedan dar demostraciones públicas de amor. "Esto es un absurdo. Si así fueran las cosas, no habría menores homosexuales en familias heterosexuales. Entonces ya es tiempo de dejar esos estigmas y creo que esta es la mejor oportunidad para sentarnos a hablar y resolver de la mano de los padres las dudas que tengan", concluye. Lo cierto, en este ir y venir de opiniones, es que tanto padres como profesionales deben afrontar que los tiempos han cambiado y que hoy es necesarios sentarse a discutir de la mano de los jóvenes el tema de la diversidad sexual. 
las parejas del mismo sexo. Asimismo, desde el año 2010, dicha corte consideró que la sentencia C336 tenía efectos retroactivos y, que además, debía otorgárseles a las parejas del mismo sexo vías idénticas para acreditar su unión permanente. Durante el trámite del caso ante la Corte IDH, el Estado planteó que reconocía la existencia de un "hecho ilícito internacional continuado, durante al menos parte del período de tiempo que estuvieron vigentes las disposiciones que no permitían el reconocimiento de las pensiones a las parejas del mismo sexo". (Corte Constitucional, Sentencia C-336 de 2008)

Así las cosas, no es desacertado decir que, si bien se han dado pasos muy importantes en lo tocante a los derechos civiles de las personas homosexuales desde la jurisprudencia constitucional, también es cierto que Colombia adolece del pronunciamiento del legislativo frente a las inquietudes de fondo que presenta la comunidad LGBTI nacional y que en últimas -aunque quizás por diferentes razones- son inquietudes y necesidades de respuesta de la comunidad nacional en general.

\section{COMENTARIOS FINALES}

Ya que han sido abiertas las puertas hacia una sociedad más incluyente y respetuosa de los derechos y deberes de todos sus integrantes, como sociedad no nos queda menos que aprender a aceptarnos con nuestras diferencias y similitudes, desde el respeto y el concepto de bien común, mientras ese paso no se haga realidad, ni la jurisprudencia, ni las creencias religiosas, ni los conceptos moralistas, ni mucho menos las leyes nos darán la tranquilidad y perspectivas hacia el futuro que como grupo social merecemos. En este mismo orden de ideas, es importante no olvidar que al conceptualizar las tipologías familiares que se identificaron en el siglo XXI, es imperativo redefinir qué es familia y su función fundamental, ya que las variantes ofrecidas desgarran roles del concepto tradicional, cubren unos y omiten otros. Sus estructuras difieren o se contraponen, permanecen o son efímeras, contrariando su paradigma. Hay diferencias de forma y esencia. Importante también resulta la cuestión de establecer lo que no es familia, a pesar de su apariencia y de que la comunidad hoy en día acepte como tal, precisamente con el fin de contar con parámetros claros a la hora de garantizar los derechos de todos los individuos, más aún a la luz de ser parte de un núcleo familiar.

Los aportes antropológicos desde las investigaciones realizadas por Virginia Gutiérrez incidieron tímidamente en la literatura jurisprudencial, existe un finísimo hilo conductor que une la realidad encontrada desde la investigación de la antropóloga colombiana con los espacios y derechos que pretende garantizar la jurisprudencia constitucional con posterioridad a 1991. Así las cosas, es importante reflexionar sobre si quizás el Legislativo y el Constituyente necesiten dar un vistazo mucho más profundo a la antropología a la hora de pretender garantizar los derechos de 
las minorías o de quienes simplemente no encuadran dentro de lo que se le impone a una sociedad como "normal", como en el caso de las personas que conforman las tipologías familiares diferentes a la "tradicional".

A su vez, es imperativo saber que no se ha dado la última palabra sobre ninguno de los temas abordados en este texto, de tal suerte que a futuro la Jurisprudencia Constitucional y la Ley se enfrentarán al reto de resolver, no solo temas relacionados con las inquietudes que se han develado a raíz de sentencias como la C-577 de 2011, sino que, a la luz de los aportes de Virginia Gutiérrez, deberán pronunciarse legalmente sobre temas como la instrumentalización de los derechos reconocidos por vía de tutela (casos individuales), las políticas públicas que garanticen el ejercicio efectivo de los derechos de minorías como las madres y padres solteros, las familias de crianza y, naturalmente, las comunidades LGBTI.

\section{REFERENCIAS}

Baena, Maria Paulina. Rincón Escalante, Juan Carlos. Torres Duarte, Juan David. [LaPulla]. (2018, Enero 25). Adivinen quiénes no van a contar para el censo - La Pulla [Archivo de video]. Recuperado de https://www.youtube.com/watch? $v=c c 4 v M J c J f q M \& v l=e s$

Constitución Política de Colombia [Const.] (1991). Edición especial preparada por el Consejo Superior de la Judicatura. Imprenta Nacional, Bogotá.

Corte Constitucional Colombiana. (2006). Sentencia C-804 de 2006. Magistrado Ponente Humberto Sierra Porto. Bogotá.

Corte Constitucional Colombiana. (2008). Sentencia C-336 de 2008. Magistrada Ponente Clara Inés Vargas Hernández. Bogotá. Corte Constitucional Colombiana. (2008). Sentencia T-1241 de 2008. Magistrada Ponente Clara Inés Vargas Hernández. Bogotá.

Corte Constitucional Colombiana. (2009). Sentencia T-911 de 2009. Magistrado Ponente Nilson Pinilla Pinilla. Bogotá.

Corte Constitucional Colombiana. (2011). Sentencia C-577 de 2011. Magistrado Ponente Gabriel Mendoza Martelo. Bogotá.

Corte Constitucional Colombiana. (2012). Sentencia T-276 de 2012. Magistrado Ponente Jorge Ignacio Pretelt Chaljub. Bogotá.

Corte Constitucional Colombiana. (2013). Sentencia T-357 de 2013. Magistrado Ponente Jorge Ignacio Pretelt Chaljub. Bogotá.

Corte Constitucional Colombiana. (2013). Sentencia T-606 de 2013. Magistrado Ponente Alberto Rojas Ríos. Bogotá.

Corte Constitucional Colombiana. (2014). Sentencia T-327 de 2014. Magistrada Ponente María Victoria Calle Correa. Bogotá. 
Corte Constitucional Colombiana. (2015). Sentencia C-071 de 2015. Magistrado Ponente Jorge Iván Palacio Palacio. Bogotá

Corte Constitucional Colombiana. (2015). Sentencia C-683 de 2015. Magistrado Ponente Jorge Iván Palacio Palacio. Bogotá.

Corte Constitucional Colombiana. (2016). Sentencia SU-214 de 2016. Magistrado Ponente Alberto Rojas Ríos. Bogotá.

Fustel de Coulanges, Numa Denys. (1997). La ciudad antigua: estudio sobre el culto, el derecho, las instituciones de Grecia y Roma. Bogotá: Editorial Panamericana.

Guerrero, C. (10 de agosto de 2016). Los temores detrás de la marcha por la familia. El Espectador. Recuperado de https://www.elespectador.com/noticias/bogota/los-temores-detras-de-marcha-familia-articulo-648506

Gutiérrez de Pineda, Virginia. (1964). La Familia en Colombia. Volumen I Trasfondo Histórico. Bogotá: Universidad Nacional de Colombia - Facultad de Sociología.

. (2000). La Familia en Colombia. Trasfondo Histórico. Medellín: Ministerio de Cultura - Universidad de Antioquia.

. (1968). Familia y Cultura en Colombia. Tipologías. Funciones y Dinámica de la Familia. Manifestaciones múltiples a través del mosaico cultural y sus estructuras sociales. Bogotá: Coediciones de Tercer Mundo y Departamento de Sociología, Universidad Nacional del Colombia.

. (1997). Familia y Cultura en Colombia. Tipologías. Funciones y Dinámica de la Familia. Manifestaciones múltiples a través del mosaico cultural y sus estructuras sociales. Medellín: Universidad de Antioquia, quinta Edición.

. (2005). Maguare. Modalidades familiares de fin de siglo. Maguaré, Número 19. 287-299. Recuperado de https://revistas.unal. edu.co/index.php/maguare/article/view/10774.

López Medina, Diego. 2016. Cómo se construyen los derechos. Narrativas jurisprudenciales sobre orientación sexual. Bogotá: Editorial LEGIS - Universidad de los Andes.

Marcha y contramarcha por la familia tradicional en Cali ( 6 de noviembre de 2018). El Tiempo, Recuperado de https://www.eltiempo. com/colombia/cali/marcha-y-contramarcha-por-la-familia-tradicional-en-cali-290224

Millán de Benavides, Carmen. 2013. Estudios de familia y agendas emergentes. Revista VIA IURIS, (15),

Molina. D., Rodríguez N. (2014 - en prensa). La concepción histórica del 
honor en el tratamiento del estupro en la Nueva Granada y en la República de Colombia. Universidad Cooperativa de Colombia, Pasto.

Pachón, Ximena. (2008). Virginia Gutiérrez de Pineda y su aporte al estudio histórico de la familia en Colombia. Maguaré, Número..19. 247-272. Recuperado de https://revistas.unal.edu.co/index.php/maguare/ article/view/10772

Razón Pública [RazónPública.com]. (2018, Enero 15). Los más y los menos del censo 2018. [Archivo de video]. Recuperado de https:// www.youtube.com/watch?v=4JiaUpaMowg

Restrepo Piedrahita Carlos. 2009. Constituciones Políticas Nacionales de Colombia. Bogotá: Universidad Externado de Colombia.

Rueda, J. (Septiembre de 2016). Virginia Gutiérrez de Pineda: Investigadora de familia y cultura en Colombia. Revista Credencial. Recuperado de http://www.revistacredencial.com/credencial/historia/ temas/virginia-gutierrez-de-pineda-investigadora-de-familia-y-cultura-en-colombia

Tafur González, Álvaro. (2015). Código Civil Colombiano Básico. Bogotá: Ediciones Leyer.

Vila de Pineda, Patricia. (2002). Virginia Gutiérrez de Pineda. 1922 - 1999. Magueré No. (15-16).

Younes Moreno, Diego. 2014. Derecho constitucional colombiano. Bogotá: Editorial LEGIS, Decimotercera edición.

(Footnotes)

1 Ver: Gutiérrez de Pineda, Virginia y Vila de Pineda Patricia. 1991. Honor, Familia y Sociedad en la Estructura Patriarcal. El caso Santander. Universidad Nacional de Colombia, Segunda Edición, Bogotá.

2 Ver: Zamudio, Lucero y Rubiano, Norma. 1991. Las separaciones conyugales en Colombia. Universidad Externado de Colombia, Bogotá.

3 Relación conyugal de alguna duración. 